\title{
OPORTUNIDADES: A EXPERIÊNCIA DA OFERTA DE CURSOS DE QUALIFICAÇÃO PROFISSIONAL NA MODALIDADE A DIST NCIA PELA SECTI - ES
}

VITÓRIA/ES JUNHO/2018

\author{
Renata Resstel - SECTI - reresstel@gmail.com \\ Aline Freitas da Silva Xavier - Ifes - alinegoval@gmail.com \\ Angela Maria Bissoli Saleme - SECTI - ambsaleme@gmail.com \\ Danielli Veiga Carneiro Sonderman - Ifes - daniellisondermann@gmail.com
}

Tipo: Relato de Experiência Inovadora (EI)

Categoria: Pesquisa e Avaliação

Setor Educacional: EDUCAÇÃO CONTINUADA EM GERAL

\section{RESUMO}

O presente trabalho tem como objetivo apresentar o Projeto Oportunidades, projeto implantado pelo Governo do Espírito Santo, a partir do Decreto no 2896-R/2011 pela Secretaria de Estado da Ciência, Tecnologia, Inovação e Educação Profissional (SECTI) como forma de treinamento e qualificação profissional, visando superar as dificuldades vividas pelo cidadão capixaba promovendo a expansão da Educação por todo território Espírito Santense. Com o projeto foram disponibilizadas no ano de 2017, 29.300 vagas em quatro ofertas distribuídas em 84 cursos.

Palavras-chave: Educação a Distância, Qualificação Profissional, Projeto Oportunidades 


\section{INTRODUÇÃO}

Com o objetivo de ampliar as oportunidades dos cidadãos capixabas se qualificarem uma vez que segundo França (2007) a competitividade e a dependência cada vez maior da tecnologia demanda da população e principalmente dos trabalhadores um aprimoramento constante em termos de educação e formação.

A Secretaria de Estado da Ciência, Tecnologia, Inovação e Educação Profissional (SECTI), por meio do Projeto OportunidadES, busca capacitar a população capixaba uma vez que entende que

Após um momento de crise pelo qual o país tem atravessado e, consequentemente, o Espírito Santo, a qualificação profissional constitui um dos principais esforços do Governo do Estado no sentido de transformar a vida da população capixaba e de qualificar trabalhadores, dos diversos segmentos do mercado, de diferentes idades e origens, para atuar com qualidade e competência, fortalecendo, dessa forma, tanto a identidade e imagem pessoal do indivíduo, quanto a do Estado, no cenário nacional e internacional. (Projeto OportunidadES, 2017, p.3)

A Educação a Distância (EaD) é excelente para atender a expectativa da SECTI uma vez que ela minimiza problema de tempo e distância e possibilita atingir o público do interior do Estado e qualquer pessoa interessadas em se qualificar, e que em alguns casos não tem no momento, condições financeiras de arcar com os custos de cursos e até deslocamento.

Com isso a comunidade espírito santense receberá cursos por meio da plataforma Modular Object-Oriented Dynamic Learning Environment (Moodle), hospedada na Instituto de Tecnologia da Informação e Comunicação do Estado do Espírito Santo (PRODEST) e desenvolvida pelo Centro Estadual de Educação Técnica (CEET) Vasco Coutinho, vinculado à SECTI, cursos de qualificação a distância, rompendo com isso, as barreiras geográficas e proporcionando flexibilidade de tempo.

O projeto Oportunidade, iniciou em abril de 2017, com a publicação do seu projeto e teve a primeira turma em maio do mesmo ano. O objetivo deste trabalho é apresentar essa experiência com cursos de qualificação profissional na modalidade a distância oferecido pela SECTI.

\section{OBJETIVO}


O objetivo geral deste trabalho é apresentar a experiência com cursos de qualificação profissional na modalidade a distância oferecido pela SECTI.

\section{REFERENCIAL TEÓRICO}

\subsection{Educação a Distância}

A Educação a Distância (EaD) é a modalidade de educação planejada por instituições que utilizam diversas tecnologias de comunicação na qual professores e alunos estão separados geograficamente. Esta modalidade de ensino, denominada EaD, é um forte contribuinte para as modificações metodológicas e tecnológicas ocorridas em todo o setor de educação e treinamento, dando acesso ao conhecimento e à certificação profissional para pessoas que antes não tinham a possibilidade de se aperfeiçoar por serem portadores de necessidades especiais, ou por morar longe dos grandes centros de estudos, ou ainda por não possuir condições econômicas para se dedicar aos estudos. Estes são alguns dos vários benefícios que a aprendizagem a distância oferece (LITTO, 2010).

Apesar de muitos defenderem o caráter inovador da ideia, a educação a distância já possui uma longa trajetória. É possível afirmar que a EaD tem a idade da escrita e sua história pode ser dividida em gerações, como são descritas por Maia; Mattar (2007, p. 21,22) Moore; Kearsley, 2007, p. 25, 32, 34, 39,44):

- Primeira geração: conhecida pelos seus cursos por correspondência surge efetivamente em meados do século XIX, em função dos meios de transporte e comunicação.

- Segunda geração: esta geração apresentou o crescimento de novas mídias como à televisão, o rádio, as fitas de áudio e vídeo e o telefone.

- Terceira geração: surge da experiência norte-americana com as universidades abertas que integravam áudio/vídeo e correspondência com orientação face a face.

- Quarta geração: EaD online, nesta geração foi introduzida a utilização de videotexto, do microcomputador, da tecnologia de multimídia, do hipertexto e de redes de computadores, caracterizando a educação a distância on-line.

- Quinta geração: esta geração é descrita como a de classes virtuais on-line com base na internet.

"No século XXI, discute-se a EAD, caracterizada pelo uso da inteligência artificial e da realidade virtual" (BATISTA, 2007, p.21). 


\subsection{Qualificação Profissional}

A temática qualificação profissional surgiu no Brasil por volta dos anos 1980. E somente na década de 90, por meio de um contexto de flexibilização das relações de trabalho é que o assunto qualificação profissional começa a fazer parte da sociedade em geral, como solução dos problemas do mercado de trabalho.

O interesse pelo tema surge com o aprofundamento da divisão do trabalho no capitalismo, desde o Adam Smith (XVIII) a Karl Marx (XIX). No século XX, com o advento da Administração Científica do Trabalho, a questão da qualificação passou a ser analisada sistematicamente (TARTUCE, 2004; FERRETI, 2004).

Ainda para Tartuce (2004), a qualificação profissional é tratada como um conjunto de práticas, visando conseguir um bom funcionamento do sistema educativo alinhado ao sistema produtivo.

Deluiz (2011) define o conceito de qualificação profissional como:

Um conjunto de conhecimentos, saberes e habilidades que provêm de várias esferas, tais como: da formação geral (conhecimento científico), da formação profissional (conhecimento técnico), e da experiência de trabalho e social (qualificações tácitas) posto em ação para resolver problemas e enfrentar situações imprevistas em uma situação concreta de trabalho. (DELUIZ, 2011, p.14)

Klein (2002) admite que as pessoas possuem habilidades diferenciadas de conhecimento, e que estas precisam ser desenvolvidas. Tais conhecimentos estão enquadrados em quatro níveis diferentes conforme quadro 1, a saber:

Quadro 01. Os quatro níveis de conhecimento

\begin{tabular}{|l|l|}
\hline Níveis de conhecimento & Descrição \\
\hline Conhecimento cognitivo (know-what) & $\begin{array}{l}\text { Refere-se ao conhecimento que os } \\
\text { profissionais atingem através de } \\
\text { treinamentos e certificações. Esse } \\
\text { conhecimento é essencial, mas não } \\
\text { suficiente para o sucesso comercial. }\end{array}$ \\
\hline Habilidades avançadas (know-how) & $\begin{array}{l}\text { E o nível em que o profissional } \\
\text { consegue executar eficazmente, os } \\
\text { conhecimentos adquiridos em }\end{array}$
\end{tabular}




\begin{tabular}{|l|l|}
\hline A compreensão dos sistemas (know- & $\begin{array}{l}\text { treinamentos e qualificações nos } \\
\text { problemas complexos do mundo real. }\end{array}$ \\
why) & $\begin{array}{l}\text { Éfundo conhecimento da teia } \\
\text { Neste nível o profissional, além de } \\
\text { executar de maneira eficaz os } \\
\text { conhecimentos em problemas, ele } \\
\text { consegue antecipar-se aos problemas } \\
\text { e consequências não previstas. }\end{array}$ \\
\hline A criatividade automotivada (care-why) & $\begin{array}{l}\text { Consistem na vontade, motivação e } \\
\text { adaptabilidade para o sucesso. É o } \\
\text { nível em que o profissional está } \\
\text { altamente motivado e criativo, sem a } \\
\text { criatividade auto motivada, os líderes } \\
\text { intelectuais perdem a vantagem de } \\
\text { conhecimento, por sua complacência. }\end{array}$ \\
\hline
\end{tabular}

Fonte: Elaborado com base no texto de Klein (2002)

O programa de qualificação profissional do Projeto OportunidadES se desenvolve no sentido de busca de colocação no mercado de trabalho, não como modelo, pois a escolha do melhor modelo está condicionado à conjunção de diversos fatores. Isso posto, podemos dizer que um modelo adequado para uma determinada Instituição pode não sê-lo para outra, uma vez que as expectativas e os desejos dos participantes são diferenciados.

\section{METODOLOGIA}

A pesquisa em que se baseia este artigo foi de natureza qualitativa do tipo estudo de caso. Este método é caracterizado como "uma pesquisa empírica que investiga um fenômeno contemporâneo dentro de seu contexto real, especialmente quando os limites entre o fenômeno e o contexto não são claramente evidentes" (YIN, 1994, p. 13).

A base teórica da pesquisa consistiu na revisão bibliográfica, abordando temas relacionados à pesquisa a fim de nivelar os conceitos e definições pertinentes a Educação a Distância e Qualificação profissional.

$\mathrm{Na}$ segunda etapa do trabalho desenvolveu-se o estudo de caso. Nessa fase foram feitas coletas e análise de dados. O objetivo desta etapa foi investigar e descrever os 
cursos online do projeto OportunidadES, seus números e consequentemente seu alcance junto a população capixaba.

\section{PROJETO OPORTUNIDADES}

Iniciado em abril de 2017, com a publicação do projeto e, efetivado em maio do mesmo ano, com a publicação do primeiro edital, com a oferta de 2 mil vagas distribuídas em nove cursos com carga horária de $80 \mathrm{~h}$ e um curso com carga horária de $60 \mathrm{~h}$. O projeto OportunidadES teve no ano de 2017 a oferta de 4 editais totalizando em 29.300 vagas ofertadas em 84 cursos.

$\mathrm{Na}$ primeira oferta (quadro 2) dos cursos na modalidade EaD teve 2.000 vagas, distribuídas em dez cursos, sendo nove com carga horária de 80h e um de 60h.

Quadro 2. Número de vagas da1ª Oferta de Cursos EaD

\begin{tabular}{|l|c|c|}
\multicolumn{1}{|c|}{ CURSOS } & CARGA HORÁRIA & VAGAS \\
\hline Criação de imagens para propaganda & $80 \mathrm{~h}$ & 200 \\
\hline customização: transformando roupas em peças novas & $80 \mathrm{~h}$ & 200 \\
\hline desenvolvimentos de sites & $80 \mathrm{~h}$ & 200 \\
\hline Empreendedorismo & $80 \mathrm{~h}$ & 200 \\
\hline Fotografia & $80 \mathrm{~h}$ & 200 \\
\hline Informática básica & $80 \mathrm{~h}$ & 200 \\
\hline Inglês básico & $80 \mathrm{~h}$ & 200 \\
\hline Introdução à programação com scratch & $80 \mathrm{~h}$ & 200 \\
\hline Marketing digital para vendas nas redes sociais & $80 \mathrm{~h}$ & 200 \\
\hline Qualidade na prestação de serviços como diferêncial competitivo & $80 \mathrm{~h}$ & 200 \\
\hline \multicolumn{2}{|c|}{ total de vagas } & $\mathbf{2 0 0 0}$ \\
\hline
\end{tabular}

Fonte: Adaptado de http://oportunidades.es.gov.br/online/index.php/edital-cursos-online/ Já na segunda oferta (quadro 3), foram ofertadas 6.900 vagas, distribuídas em 23 cursos com carga horária de 80h cada.

Quadro 3. Número de vagas da $2^{2}$ Oferta de Cursos EaD 


\begin{tabular}{|l|c|c|}
\multicolumn{1}{|c|}{ CURSOS } & CARGA HORÁRIA & VAGAS \\
\hline Criação de imagens para propaganda & $80 \mathrm{~h}$ & 300 \\
\hline customização: transformando roupas em peças novas & $80 \mathrm{~h}$ & 300 \\
\hline desenvolvimentos de sites & $80 \mathrm{~h}$ & 300 \\
\hline Empreendedorismo & $80 \mathrm{~h}$ & 300 \\
\hline Fotografia & $80 \mathrm{~h}$ & 300 \\
\hline informática básica & $80 \mathrm{~h}$ & 300 \\
\hline inglès básico & $80 \mathrm{~h}$ & 300 \\
\hline marketing digital para vendas nas redes sociais & $80 \mathrm{~h}$ & 300 \\
\hline qualidade na prestação de serviços como diferêncial competitivo & $80 \mathrm{~h}$ & 300 \\
\hline Administração de estoque e armazenamento & $80 \mathrm{~h}$ & 300 \\
\hline Android Básico & $80 \mathrm{~h}$ & 300 \\
\hline Criação de sites de vendas na web & $80 \mathrm{~h}$ & 300 \\
\hline Criando gráficos no excel & $80 \mathrm{~h}$ & 300 \\
\hline Customização de roupas & $80 \mathrm{~h}$ & 300 \\
\hline Inglês intermediário & $80 \mathrm{~h}$ & 300 \\
\hline Marketing na internet & $80 \mathrm{~h}$ & 300 \\
\hline Primeiros passos para montar um negócio & $80 \mathrm{~h}$ & 300 \\
\hline Tecnico em manutenção de computadores & $80 \mathrm{~h}$ & 300 \\
\hline Word básico & $80 \mathrm{~h}$ & 300 \\
\hline Maquiador & $80 \mathrm{~h}$ & 300 \\
\hline Panificação & $80 \mathrm{~h}$ & 300 \\
\hline Porteiro & $80 \mathrm{~h}$ & 300 \\
\hline recepcionista & $80 \mathrm{~h}$ & 300 \\
\hline & & 6900 \\
\hline
\end{tabular}

Fonte: Adaptado de http://oportunidades.es.gov.br/online/index.php/edital-cursos-online/

Na sua terceira oferta (quadro 4) o projeto Oportunidade ofereceu 10.800 vagas, em 27 cursos com carga horária de 80h cada.

Quadro 4. Número de vagas da 3ª Oferta de Cursos EaD

\begin{tabular}{|l|c|c|}
\multicolumn{1}{|c|}{ CURSOS } & CARGA HORÁRIA & VAGAS \\
\hline Administraçäo de estoque e armazenamento & $80 \mathrm{~h}$ & 400 \\
\hline Android & $80 \mathrm{~h}$ & 400 \\
\hline Camareira & $80 \mathrm{~h}$ & 400 \\
\hline Confeitaria Básica & $80 \mathrm{~h}$ & 400 \\
\hline Cozinhando com microondas & $80 \mathrm{~h}$ & 400 \\
\hline Customização em roupas de bebê & $80 \mathrm{~h}$ & 400 \\
\hline Desenvolvimentos de sites & $80 \mathrm{~h}$ & 400 \\
\hline Empreendedorismo & $80 \mathrm{~h}$ & 400 \\
\hline Fotografia & $80 \mathrm{~h}$ & 400 \\
\hline Garçom & $80 \mathrm{~h}$ & 400 \\
\hline Gestão de salão de beleza & $80 \mathrm{~h}$ & 400 \\
\hline Gestão financeira de pequenas e médias empresas & $80 \mathrm{~h}$ & 400 \\
\hline iformática básica & $80 \mathrm{~h}$ & 400 \\
\hline Inglês intermediário & $80 \mathrm{~h}$ & 400 \\
\hline inglês avançado & $80 \mathrm{~h}$ & 400 \\
\hline Maquiador & $80 \mathrm{~h}$ & 400 \\
\hline Maquiagem para festas & $80 \mathrm{~h}$ & 400 \\
\hline Marketing digital para vendas nas redes sociais & $80 \mathrm{~h}$ & 400 \\
\hline Marketing para pequenas empresas & $80 \mathrm{~h}$ & 400 \\
\hline Panificação & $80 \mathrm{~h}$ & 400 \\
\hline Porteiro & $80 \mathrm{~h}$ & 400 \\
\hline Preparação de massas frescas & $80 \mathrm{~h}$ & 400 \\
\hline Preparo de carnes, aves e peixes & $80 \mathrm{~h}$ & 400 \\
\hline Preparo de docinhos para festas & $80 \mathrm{~h}$ & 400 \\
\hline Recepcionista & $80 \mathrm{~h}$ & 400 \\
\hline Manutenção de computadores & $80 \mathrm{~h}$ & 400 \\
\hline qualidade na prestaçäo de serviços como diferêncial competitivo & $80 \mathrm{~h}$ & 400 \\
\hline & & 10800 \\
\hline & & \\
\hline
\end{tabular}

Fonte: Adaptado de http://oportunidades.es.gov.br/online/index.php/edital-cursos-online/

$\mathrm{Na}$ quarta e última oferta (quadro 4) de 2017, dos cursos EaD, oferecidos pela SECTI, 
foram disponibilizadas 9.600 vagas em 24 cursos, com carga horária de 80h cada.

Quadro 5. Número de vagas da 4ª Oferta de Cursos EaD

\begin{tabular}{|l|c|c|}
\multicolumn{1}{|c|}{ CURSOS } & CARGA HORÁRIA & VAGAS \\
\hline Administração de condominio & $80 \mathrm{~h}$ & 300 \\
\hline Administraçäo de estoque e armazenamento & $80 \mathrm{~h}$ & 300 \\
\hline Automaquiagem & $80 \mathrm{~h}$ & 300 \\
\hline Balconista de Farmácia & $80 \mathrm{~h}$ & 300 \\
\hline Cerimonial e protocolo & $80 \mathrm{~h}$ & 300 \\
\hline construção de curriculo e apresentaçäo em entrevistas & $80 \mathrm{~h}$ & 300 \\
\hline fluxo de caixa & $80 \mathrm{~h}$ & 300 \\
\hline fotografia & $80 \mathrm{~h}$ & 300 \\
\hline Gestão financeira de pequenas e médias empresas & $80 \mathrm{~h}$ & 300 \\
\hline Informática avançada & $80 \mathrm{~h}$ & 300 \\
\hline informática básica & $80 \mathrm{~h}$ & 300 \\
\hline inglês avançado & $80 \mathrm{~h}$ & 300 \\
\hline inglês básico & $80 \mathrm{~h}$ & 300 \\
\hline inglês intermediário & $80 \mathrm{~h}$ & 300 \\
\hline Inglês para viagens & $80 \mathrm{~h}$ & 300 \\
\hline Logistica & $80 \mathrm{~h}$ & 300 \\
\hline Maquiador & $80 \mathrm{~h}$ & 300 \\
\hline Marketing digital para vendas nas redes sociais & $80 \mathrm{~h}$ & 300 \\
\hline Montagem e manutençäo de computadores & $80 \mathrm{~h}$ & 300 \\
\hline Porteiro & $80 \mathrm{~h}$ & 300 \\
\hline Recepcionista & $80 \mathrm{~h}$ & 300 \\
\hline Secretaria escolar & $80 \mathrm{~h}$ & 300 \\
\hline tecnica de vendas & $80 \mathrm{~h}$ & 300 \\
\hline tecnicas de redação & $80 \mathrm{~h}$ & 300 \\
\hline & & 9600 \\
\hline \multicolumn{1}{|c|}{ Total } & &
\end{tabular}

Fonte: Adaptado de http://oportunidades.es.gov.br/online/index.php/edital-cursos-online/

Foram ofertadas, no ano de 2017 vinte e nove mil e trezentas (29.300) vagas em 54 diferentes cursos, tendo aproximadamente 50 mil inscritos. Com estes números é possível perceber a necessidade e busca de qualificação profissional pela população capixaba, mostrando a importância e a eficácia da educação a distância.

Esta modalidade de ensino permitiu atender a população de $80 \%$ dos municípios capixabas, contribuindo com o aprimoramento de seus conhecimentos profissionais e fornecendo subsídios para sua inserção e/ou recolocação no mundo do trabalho.

Esses números vão de encontro ao que DELUIZ (2011) nos apresenta como sendo qualificação profissional, "conjunto de conhecimentos, saberes e habilidades que provêm de várias esferas" (DELUIZ, 2011, p.14), ou seja, o projeto oportunidadES está conseguindo ser uma dessas esferas a da formação profissional.

Outro ponto importante que se deve refletir, é que as ofertas de 54 tipos diferentes de curso permitiu ao projeto também atender ao que Klein (2002) nos expõe ao admitir que 
as pessoas possuem habilidades diferenciadas de conhecimento, e que estas precisam ser desenvolvidas.

Os cursos ofertados pelo Projeto OportunidadES têm duração variada, desde minicursos com 04 (quatro) horas de duração a cursos com 200 (duzentas) horas, variando de acordo com a ementa proposta.

As vagas ofertadas para qualificação atendem às demandas das comunidades, à vocação econômica da região, ao mundo do trabalho, aos setores produtivos e aos programas governamentais, tanto estaduais quanto federais.

\section{Referências}

BATISTA, Márcia Luiza França da Silva.Design instrucional: uma abordagem do design gráfico para o desenvolvimento de ferramentas de suporte à Educação a Distância. Dissertação (Mestrado) - Universidade Estadual Paulista. Faculdade de Arquitetura, Artes e Comunicação, Bauru, 2008.

DELUIZ, Neise. Qualificação profissional, trabalho e formação: qualificação, trajetória ocupacional e subjetividade. 2011. Disponível em: . Acesso em: 10 de abr. de 2014.

FRANÇA, Sérgio Carlos. Treinamento a Distância como Ferramenta para Capacitação Profissional. Florianópolis: 2007

KLEIN, David A. A gestão estratégica do capital intelectual: recursos para a economia baseada no conhecimento. Rio de Janeiro: Qualitymark, 2002

LITTO Fredric M. Litto. Aprendizagem a distância. 1a. ed. -- São Paulo: Imprensa Oficial, 2010.

MAIA, C.; MATTAR, J. ABC da EaD: a educação a distância hoje. 1. ed. São Paulo: Pearson Prentice Hall, 2007

TARTUCE, G.L.B.P. Algumas reflexões sobre a qualificação do trabalho a partir da sociologia francesa do pós-guerra. Educação e Sociedade, Campinas, vol. 25, n.87, p. 353- 382, maio/ago. 2004. Disponível em: . Acesso em 10 de abr. de 2014.

Moore, M. G.; Kearsley, G. Educação a distância: uma visão integrada. São Paulo: 
Cengage Learning. 2008.

Yin, R. K. (1994). Pesquisa Estudo de Caso - Desenho e Métodos (2 ed.). Porto Alegre: Bookman. 